\title{
Large-Area Accurate Position Registry of Microparticles on Flexible, Stretchable Substrates by Using Elastomer Templates
}

Kunsuk Koh, ${ }^{1+}$ Hyejin Hwang, ${ }^{1+}$ Choojin Park, ${ }^{2}$ Jae Yong Lee, ${ }^{3}$ Tae Yoon Jeon, ${ }^{4}$ Shin-Hyun Kim, ${ }^{4}$ Jin Kon Kim, ${ }^{3}$ Unyong Jeong ${ }^{1 *}$

${ }^{1}$ Department of Materials Science and Engineering, POSTECH, 77 Cheongam-Ro, Nam-Gu, Pohang, Gyeongbuk, Korea 790-784

${ }^{2}$ Department of Materials Science and Engineering, Yonsei University, 134 Shinchon-dong, Seoul, Korea

${ }^{3}$ Department of Chemical Engineering, POSTECH, 77 Cheongam-Ro, Nam-Gu, Pohang, Gyeongbuk, Korea 790-784

${ }^{4}$ Department of Chemical and Biomolecular Engineering, KAIST, Daejeon, Korea 305-701

+ The authors contributed equally to this work.

*Corresponding author: ujeong@ postech.ac.kr 

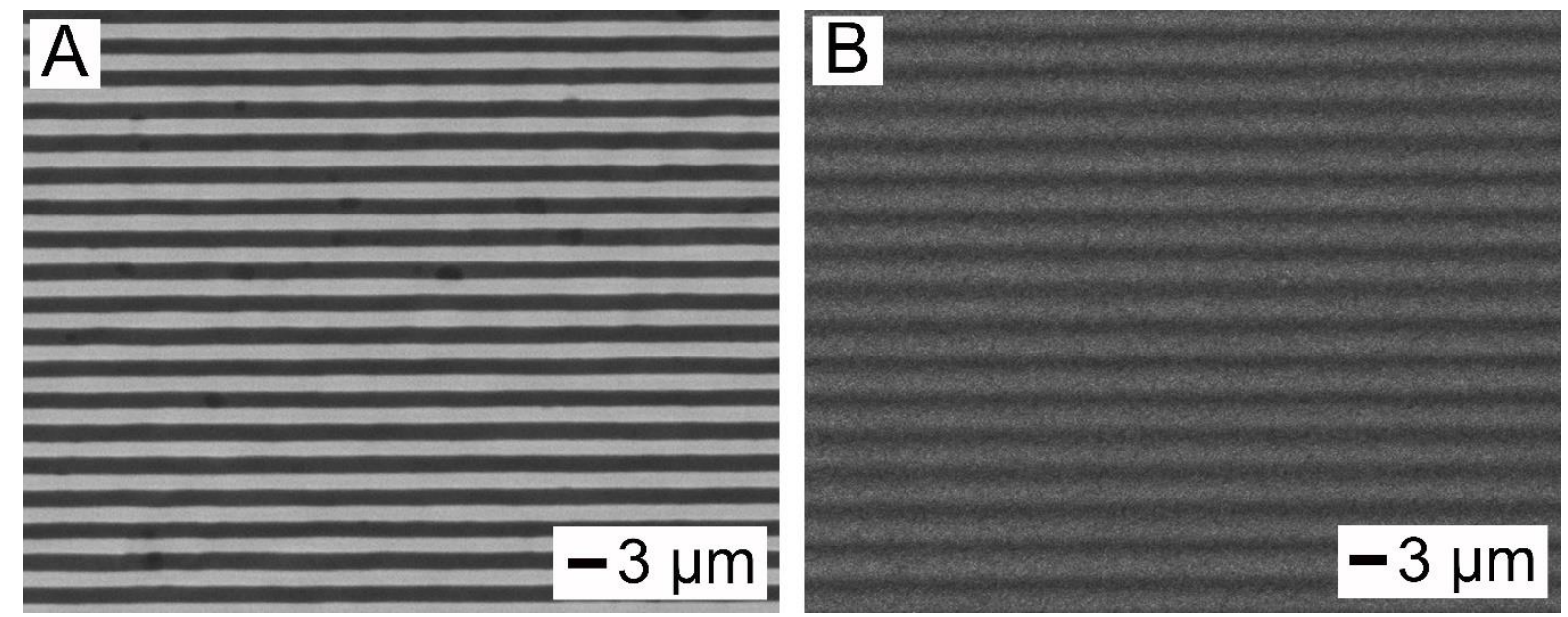

Figure S1. SEM images of line-space patterns with the periodicities of $0.97 P_{\mathrm{o}}(2.51 \mu \mathrm{m})(\mathrm{A})$ and $1.03 P_{\mathrm{o}}(2.67 \mu \mathrm{m})(\mathrm{B})$.
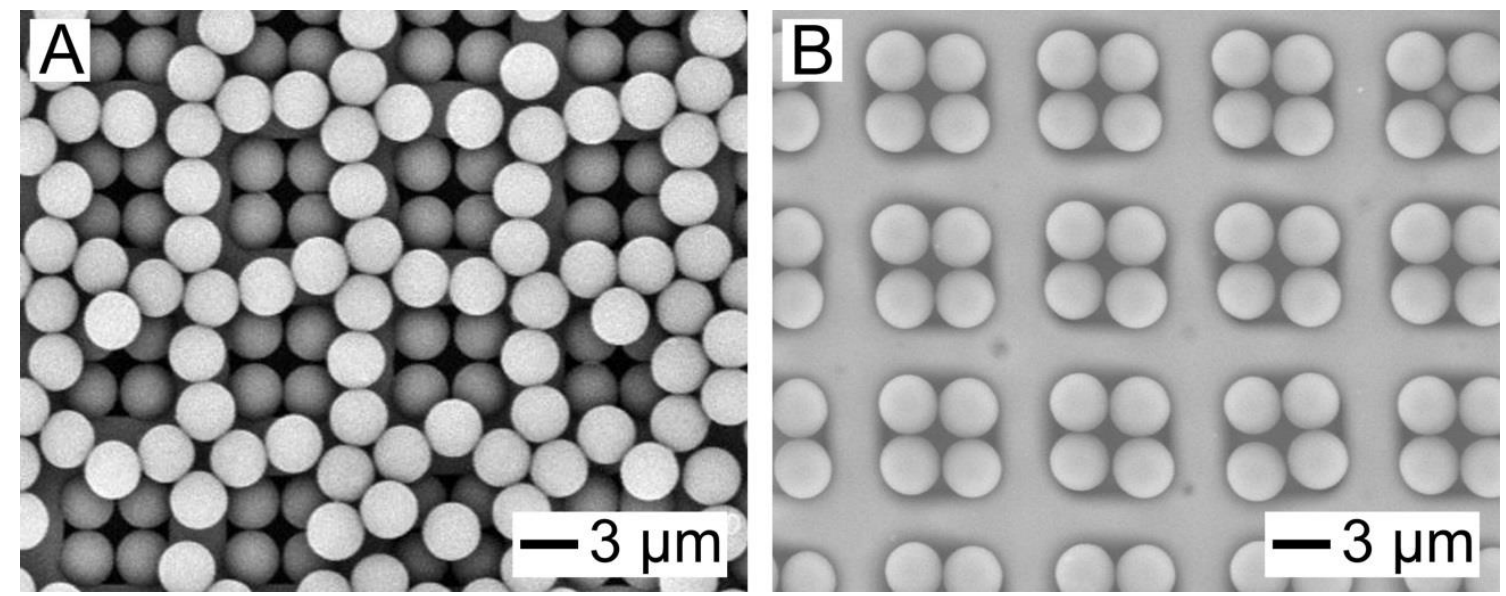

Figure S2. SEM images of before (A) and after (B) upper $3 \mu \mathrm{m}$ polystyrene particles were removed by rubber piece with higher tack energy. 

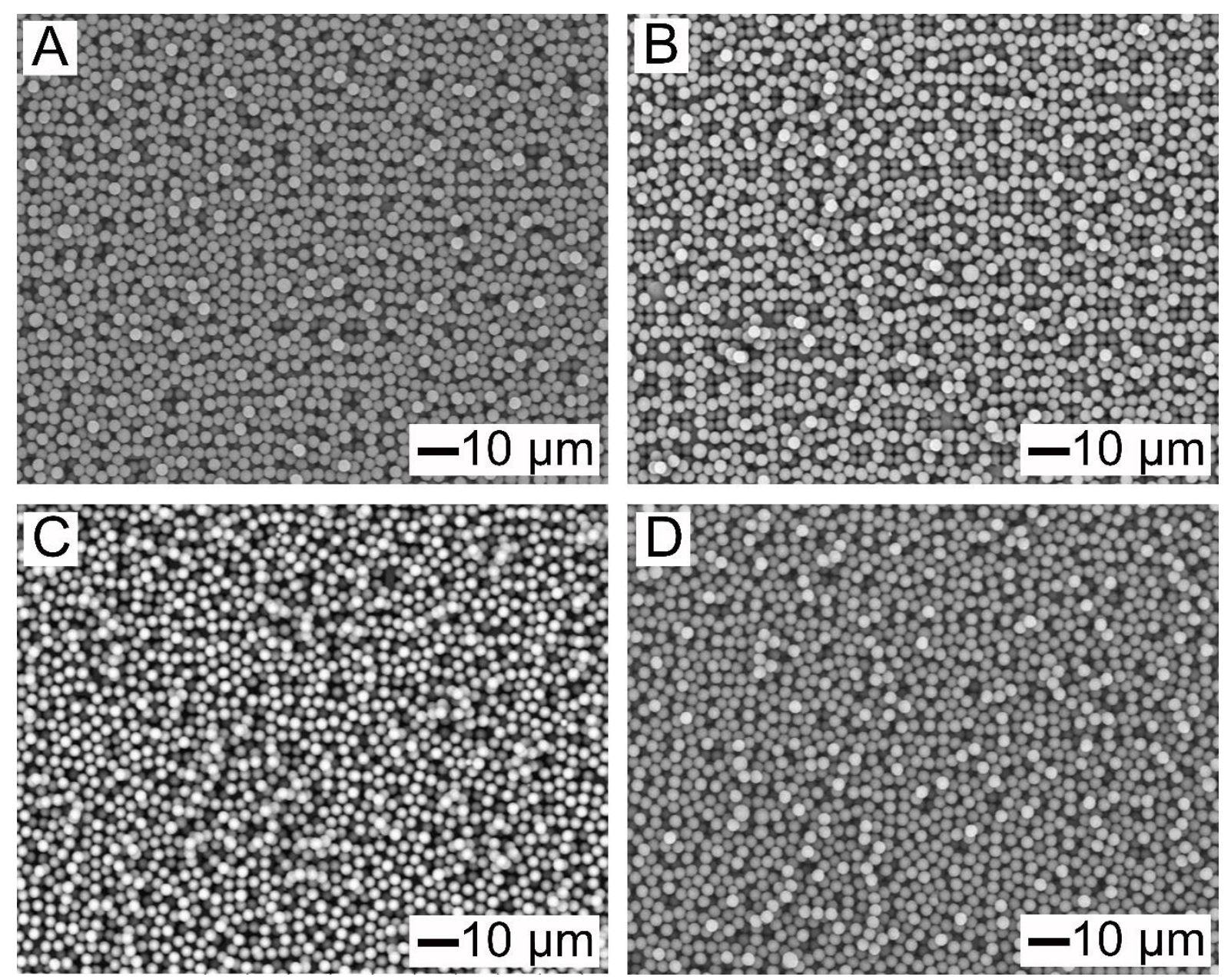

Figure S3. SEM images of particles arrayed in $6 \times 6 \mu \mathrm{m}$ wells in case of Rubbing speed at (A)

$1 \mathrm{~mm} \mathrm{~s}^{-1}$, (B) $2 \mathrm{~mm} \mathrm{~s}^{-1}$ (C) $4 \mathrm{~mm} \mathrm{~s}^{-1}$ (D) $8 \mathrm{~mm} \mathrm{~s}^{-1}$. Pressure was fixed at $1 \mathrm{~kg} \mathrm{~cm}^{-2}$. PS beads

$(3 \mu \mathrm{m}$ in diameter $)$ were used. Unit area $(150 \times 112 \mu \mathrm{m})$ had 234 wells $(18 \times 13$ wells $)$. 

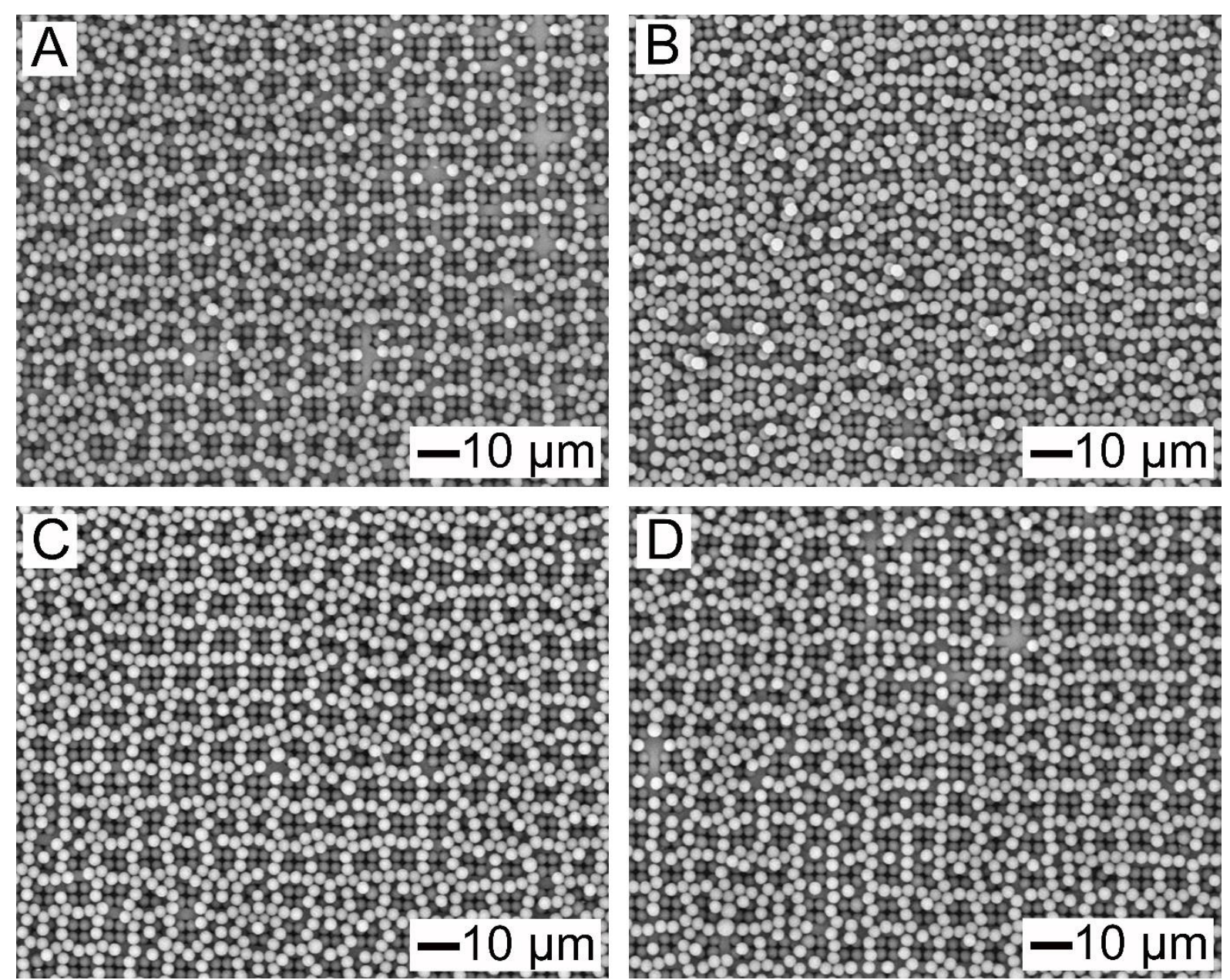

Figure S4. SEM images of particles arrayed in $6 \times 6 \mu \mathrm{m}$ wells in case of Rubbing speed at (A)

$1 \mathrm{~mm} \mathrm{~s}^{-1}$, (B) $2 \mathrm{~mm} \mathrm{~s}^{-1}$ (C) $4 \mathrm{~mm} \mathrm{~s}^{-1}$ (D) $8 \mathrm{~mm} \mathrm{~s}^{-1}$. Pressure was fixed at $1.5 \mathrm{~kg} \mathrm{~cm}^{-2}$. PS beads

$(3 \mu \mathrm{m}$ in diameter) were used. Unit area $(150 \times 112 \mu \mathrm{m})$ had 234 wells $(18 \times 13$ wells $)$. 

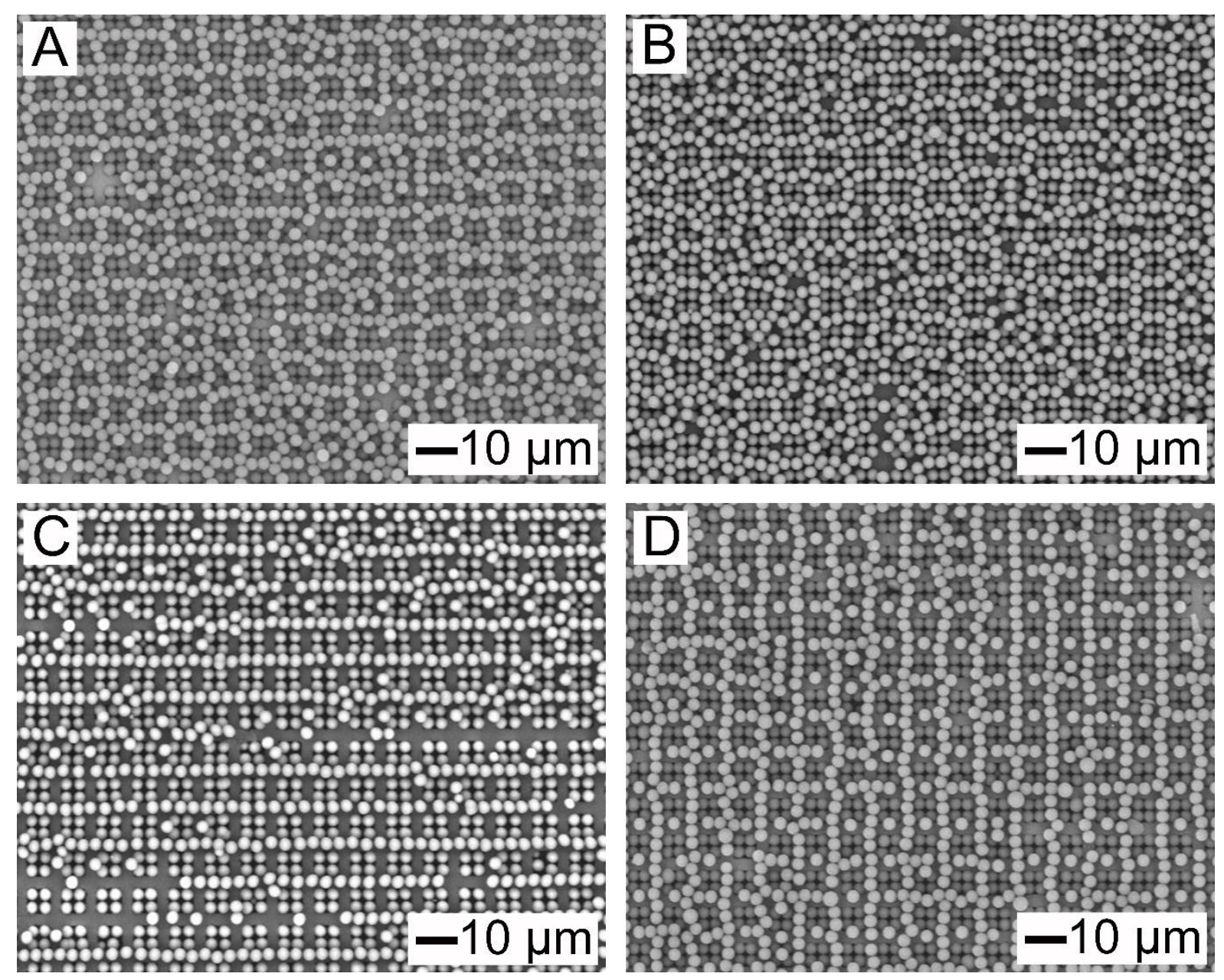

Figure S5. SEM images of particles arrayed in $6 \times 6 \mu \mathrm{m}$ wells in case of Rubbing speed at (A)

$1 \mathrm{~mm} \mathrm{~s}^{-1}$, (B) $2 \mathrm{~mm} \mathrm{~s}^{-1}$ (C) $4 \mathrm{~mm} \mathrm{~s}^{-1}$ (D) $8 \mathrm{~mm} \mathrm{~s}^{-1}$. Pressure was fixed at $2 \mathrm{~kg} \mathrm{~cm}^{-2}$. PS beads

$(3 \mu \mathrm{m}$ in diameter $)$ were used. Unit area $(150 \times 112 \mu \mathrm{m})$ had 234 wells $(18 \times 13$ wells $)$. 

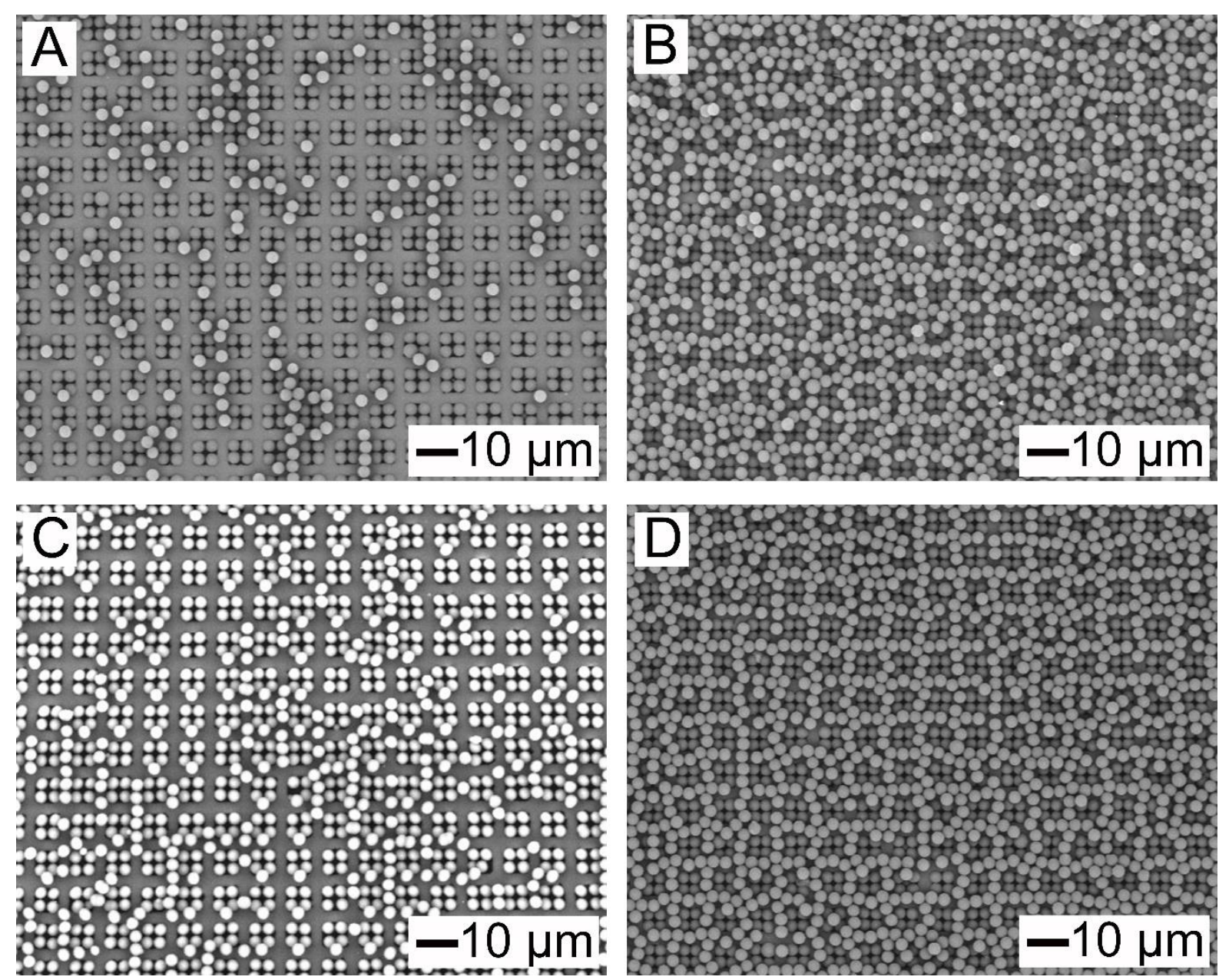

Figure S6. SEM images of particles arrayed in $6 \times 6 \mu \mathrm{m}$ wells in case of Rubbing speed at (A)

$1 \mathrm{~mm} \mathrm{~s}^{-1}$, (B) $2 \mathrm{~mm} \mathrm{~s}^{-1}$ (C) $4 \mathrm{~mm} \mathrm{~s}^{-1}$ (D) $8 \mathrm{~mm} \mathrm{~s}^{-1}$. Pressure was fixed at $2.5 \mathrm{~kg} \mathrm{~cm}^{-2}$. PS beads

$(3 \mu \mathrm{m}$ in diameter $)$ were used. Unit area $(150 \times 112 \mu \mathrm{m})$ had 234 wells $(18 \times 13$ wells $)$. 

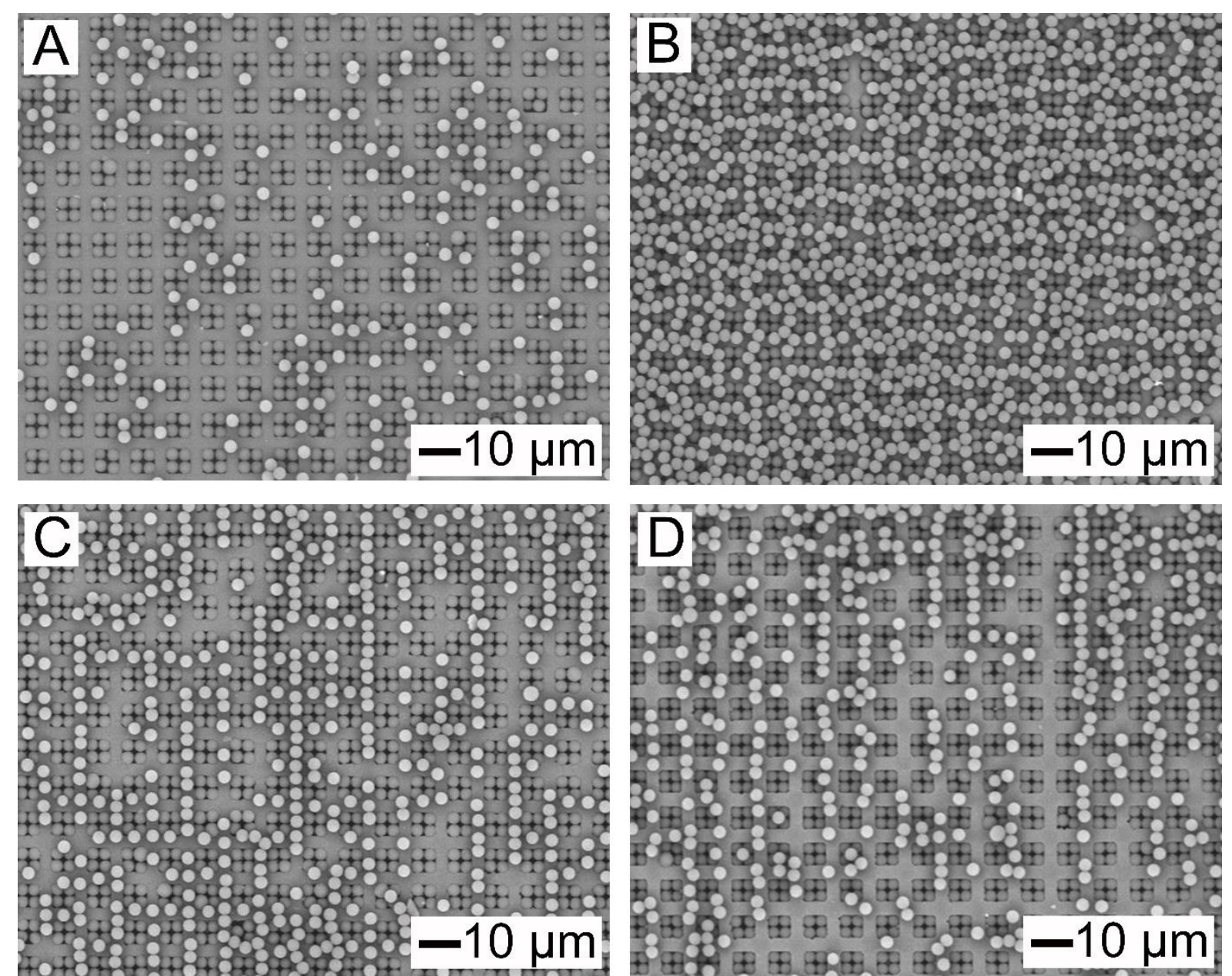

Figure S7. SEM images of particles arrayed in $6 \times 6 \mu \mathrm{m}$ wells in case of Rubbing speed at (A)

$1 \mathrm{~mm} \mathrm{~s}^{-1}$, (B) $2 \mathrm{~mm} \mathrm{~s}^{-1}$ (C) $4 \mathrm{~mm} \mathrm{~s}^{-1}$ (D) $8 \mathrm{~mm} \mathrm{~s}^{-1}$. Pressure was fixed at $3 \mathrm{~kg} \mathrm{~cm}^{-2}$. PS beads

$(3 \mu \mathrm{m}$ in diameter $)$ were used. Unit area $(150 \times 112 \mu \mathrm{m})$ had 234 wells $(18 \times 13$ wells $)$. 


\begin{tabular}{lccccc}
\hline & $\begin{array}{c}\mathbf{1} \\
\left(\mathrm{kg} \mathrm{cm}^{-2}\right)\end{array}$ & $\begin{array}{c}\mathbf{1 . 5} \\
\left(\mathrm{kg} \mathrm{cm}^{-2}\right)\end{array}$ & $\begin{array}{c}\mathbf{2} \\
\left(\mathrm{kg} \mathrm{cm}^{-2}\right)\end{array}$ & $\begin{array}{c}\mathbf{2 . 5} \\
\left(\mathrm{kg} \mathrm{cm}^{-2}\right)\end{array}$ & $\begin{array}{c}\mathbf{3} \\
\left(\mathrm{kg} \mathrm{cm}^{-2}\right)\end{array}$ \\
\hline $\mathbf{1}\left(\mathbf{m m} / \mathrm{s}^{-1}\right)$ & 4 & 4 & 4 & 4 & 4 \\
\hline $\mathbf{2}\left(\mathbf{m m} / \mathbf{s}^{-1}\right)$ & 4 & 4 & 4 & 4 & 3.99 \\
\hline $\mathbf{4}\left(\mathbf{m m} / \mathrm{s}^{-1}\right)$ & 4 & 4 & 4.02 & 3.99 & 3.98 \\
\hline $\mathbf{8}\left(\mathbf{m m} / \mathrm{s}^{-1}\right)$ & 4 & 4 & 4 & 4.01 & 4 \\
\hline
\end{tabular}

Supporting Table S1. Average value of the number of particles ( $3 \mu \mathrm{m}$ PS) in the physical well $(6 \times 6 \mu \mathrm{m})$ at each conditions. This table was made up the results of Figure S4-8. The first row is the rubbing speed and the first line is the normal pressure applied. Almost every particle was positioned easily in the wells regardless of the rubbing speed. It shows that the rubbing speed and pressure are not critical conditions for the particle assembly in the well.

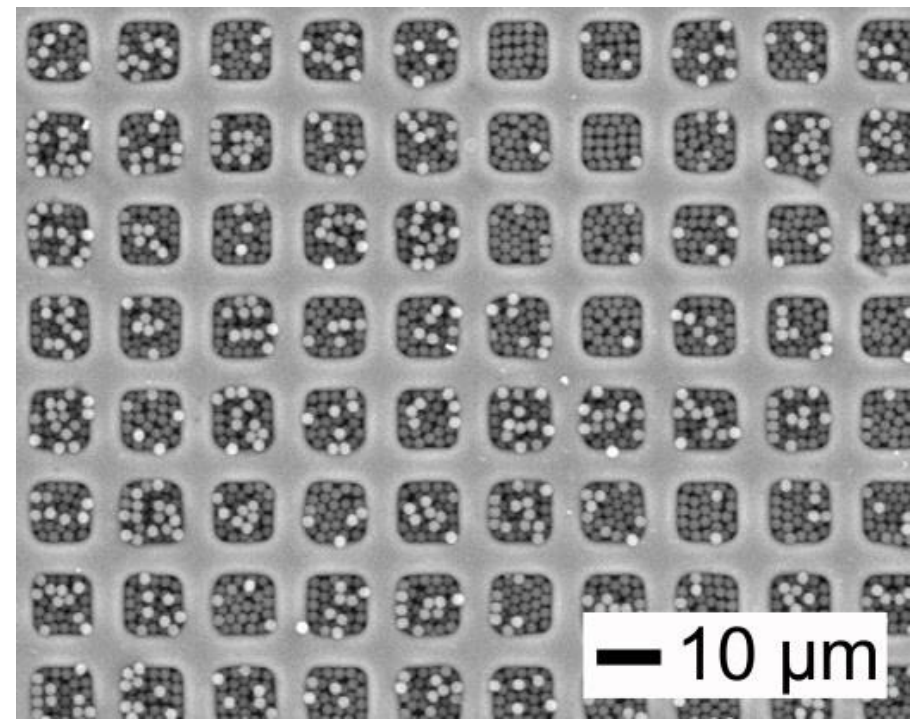

Figure S8. SEM image of $2 \mu \mathrm{m}$ polystyrene particles placed in the physical well (well depth: $2 \mu \mathrm{m}, 1 \mathrm{D})$. Since the well depth was too large for the particles, (>0.8D) particles did not have a specific array in the wells. Side lengths of the wells were $10 \mu \mathrm{m}$. 


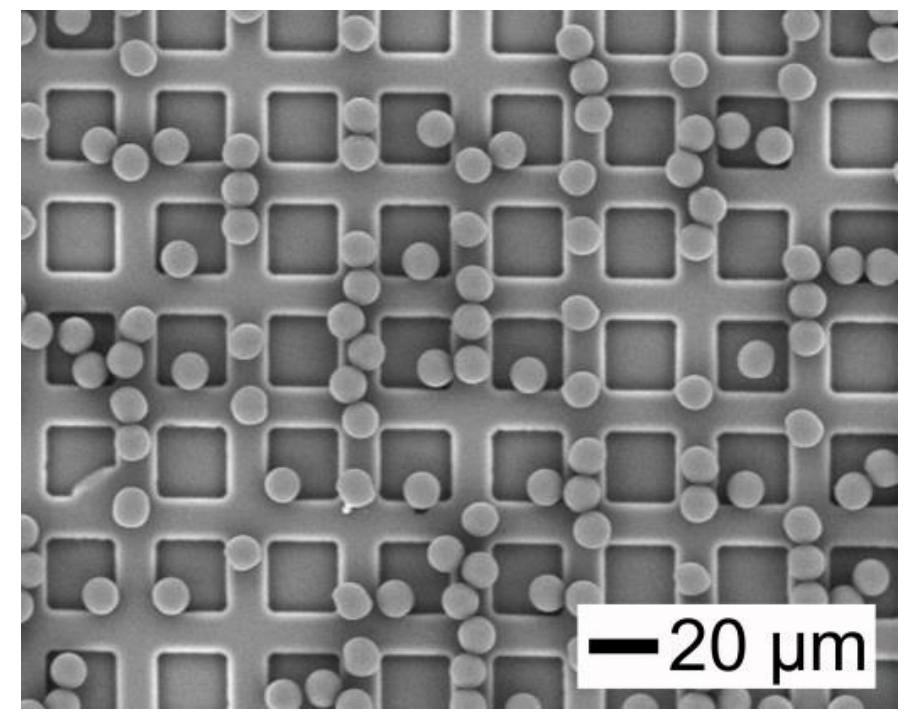

Figure S9. SEM image of $10 \mu \mathrm{m}$ polystyrene particles placed in the physical wells (well depth:

$2 \mu \mathrm{m}, 0.2 \mathrm{D})$. The particles were not assembled in the well. Side length of the well was $20 \mu \mathrm{m}$.

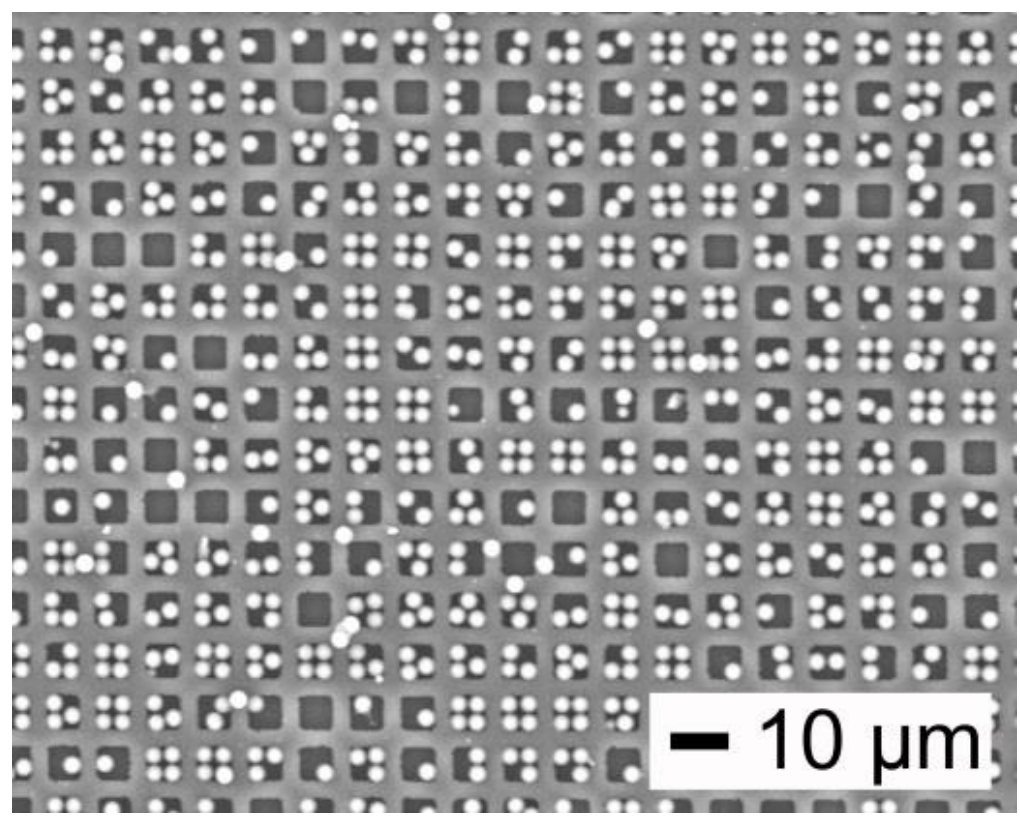

Figure S10. SEM image of $3 \mu \mathrm{m}$ polystyrene particles placed in the wells by uniaxial rubbing.

Rubbing in a single direction generally placed three particles in each well in a triangle shape. 